See Article page 394

\section{Commentary: What has the coronavirus disease 2019 (COVID-19) pandemic really taught us?}

\author{
Hanghang Wang, MD, $\mathrm{PhD}$, and Ahmet Kilic, MD
}

In an effort to compare cardiothoracic surgical training before and during the coronavirus disease 2019 (COVID-19) pandemic, Shafi and colleagues ${ }^{1}$ conducted a crosssectional survey among cardiothoracic surgery trainees in the United Kingdom. In the survey, the majority of trainees reported that COVID-19 has had a negative impact on their training. This is evidenced by significant decreases in both case volume and resident autonomy. Specifically, the number of allocated theater sessions decreased, and trainees were frequently pulled away from cardiothoracic training through changes in job role or redeployment. Decrease in resident autotomy is demonstrated by significant reduction in the percentage of cases performed by trainees as the primary operator.

Before the COVID-19 pandemic, various shortcomings of cardiothoracic surgery education had already been brought to light. ${ }^{2}$ These shortcomings are a result of rapidly developing technologies, increasing case complexity, heightened scrutiny over outcomes, and restrictions on resident work hours. During the pandemic, these shortcomings are further confounded and amplified by the relative isolationism that we feel as a society.

This study highlights current challenges in cardiothoracic surgical training imposed by the COVID-19 pandemic. These challenges are not unique to the United Kingdom; globally, cardiothoracic surgery trainees have experienced a significant reduction in operative volume, case complexity, and other clinical and educational

\footnotetext{
From Cardiothoracic Surgery, The Johns Hopkins Hospital, Baltimore, Md. Disclosures: The authors reported no conflicts of interest.

The Journal policy requires editors and reviewers to disclose conflicts of interest and to decline handling or reviewing manuscripts for which they may have a conflict of interest. The editors and reviewers of this article have no conflicts of interest.

Received for publication July 26, 2021; revisions received July 26, 2021; accepted for publication July 26, 2021; available ahead of print Aug 13, 2021.

Address for reprints: Ahmet Kilic, MD, Division of Cardiac Surgery, The Johns Hopkins Hospital, 1800 Orleans St, Zayed 7107, Baltimore, MD 21287 (E-mail: akilic2@jhmi.edu).

JTCVS Open 2021;7:413-4

2666-2736

Copyright (c) 2021 The Author(s). Published by Elsevier Inc. on behalf of The American Association for Thoracic Surgery. This is an open access article under the CC BY-NC-ND license (http://creativecommons.org/licenses/by-nc-nd/4.0/)

https://doi.org/10.1016/j.xjon.2021.07.026
}

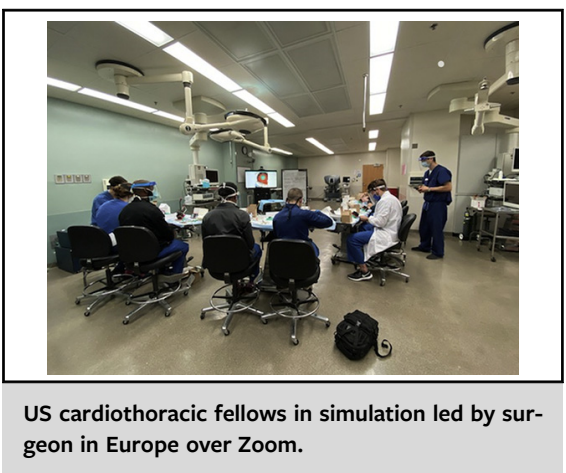

CENTRAL MESSAGE

The COVID-19 pandemic has had a negative impact on cardiothoracic trainees. We need to revamp, rethink, and use different type of resources, such as simulation, to improve the training and education.

opportunities. $^{3}$ Downstream effects of COVID-19 could include inadequate surgical skills, inability to fulfill case requirements for board certification, and most importantly, unpreparedness for independent practice after graduation from training.

In light of these challenges, the authors proposed a potential solution to the challenges as a result of COVID-19-simulation. Simulation-based skill training has been increasingly recognized as an important solution to address the challenges in cardiothoracic training. ${ }^{4}$ In this survey, simulation was acknowledged by the majority of trainees as an important tool in improving surgical skills. In addition, the majority of trainees thought that simulation, such as animal wet labs, should be used to enhance training and education.

In our own institutional experience, simulation has greatly enhanced resident training during the COVID-19 pandemic. For instance, our cardiothoracic surgery fellows recently performed mitral valve repairs and replacements on pig hearts, led by our faculty expert in the wet lab. Before this, our fellows participated in simulation sessions on our US campus led by a surgeon expert in Europe via Zoom. The fellows performed coronary anastomosis and aortic root replacements in the wet lab, receiving instructions and immediate feedback via Zoom.

During the ongoing COVID-19 pandemic, cardiothoracic surgery training is facing many challenges. Although these 
challenges are not unique to cardiothoracic education, it is most intensified because of the focus and repetition required to both achieve proficient technical skills and acquire sound clinical judgment. This pandemic has made us rethink the way we teach, the way we interact, and the importance of our time together. We need to continue to innovate not only in practice but also in how we teach and communicate with one another and view this difficult time as an important opportunity for us to revamp, rethink, and use different type of resources to improve the training and education.

\section{References}

1. Shafi AMA, Sheikh AM, Awad WI. Comparison of cardiothoracic surgical training before and during the COVID-19 pandemic in the United Kingdom. $J$ Thorac Cardiovasc Surg Open. 2021;7:394-410.

2. Vaporciyan A, Yang SC, Baker CJ, Fann JI, Verrier ED. Cardiothoracic surgery residency training: past, present, and future. J Thorac Cardiovasc Surg. 2013; 146:759-67.

3. Fuller S, Vaporciyan A, Dearani JA, Stulak JM, Romano JC. COVID-19 disruption in cardiothoracic surgical training: an opportunity to enhance education. Ann Thorac Surg. 2020;110:1443-6.

4. Ribeiro IB, Ngu JMC, Buu-Khanh L, Edwards RA. Simulation-based skill training for trainees in cardiac surgery: a systematic review. Ann Thorac Surg. 2018;105: 972-82. 